\title{
Urdimento
}

Revista de Estudos em Artes Cênicas E-ISSN: 2358.6958

\section{A geometria do espaço e do gesto em cena: uma leitura de Os arqueólogos}

Cassia Costa Lopes

\section{Para citar este artigo:}

LOPES, Cassia Costa. A geometria do espaço e do gesto em cena: uma leitura de Os arqueólogos. Urdimento, Florianópolis, v. 3, n. 39, nov./dez. 2020.

DOI: http:/dx.doi.org/10.5965/14145731033920200203

Este artigo passou pelo Plagiarism Detection Software | iThenticate 
A geometria do espaço e do gesto em cena: uma leitura de Os arqueólogos

Cassia Costa Lopes ${ }^{1}$

\section{Resumo}

Este ensaio volta-se para a análise do texto dramatúrgico Os arqueólogos, do escritor paulista Vinicius Calderoni, tendo em vista uma reflexão sobre a noção do espaço e do gesto a partir da avaliação dos procedimentos de construção textual dramática e seus desdobramentos filosóficos. Consideram-se as especificidades da paisagem da dramaturgia contemporânea, a fragmentação da fábula, do mythos, no desenho da escrita episódica e sua relação com a crônica fotográfica dos tempos atuais.

Palavras-chave: Dramaturgia. Espaço. Gesto. Teoria. Catástrofe.

The geometry of space and gesture in scene: a reading of Os arqueólogos

\section{Abstract}

This essay focuses on the analysis of the dramaturgical text Os arqueólogos, by Vinicius Calderoni, a writer from São Paulo, offering a reflection on the notion of space and gesture from the evaluation of dramatic textual construction procedures and their philosophical developments. The specificities of the landscape of contemporary dramaturgy, the fragmentation of the fable, and the mythos are considered in the design of episodic writing and its relationship with the photographic chronicle of the present times.

Keywords: Dramaturgy. Space. Gesture. Theory. Catastrophe.

La geometria del espacio y el gesto en escena: una lectura de Os arqueólogos

\section{Resumen}

Este ensayo se centra en el análisis del texto dramatúrgico Os arqueólogos, del escritor paulista Vinicius Calderoni, con el objetivo de reflexionar sobre la noción de espacio y gesto desde la evaluación de los dramáticos procedimientos de construcción textual y sus desarrollos filosóficos. Las especificidades del paisaje de la dramaturgia contemporánea, la fragmentación de la fábula, los mitos, se consideran en el diseño de la escritura episódica y su relación con la crónica fotográfica de los tiempos actuales.

Palabras clave: Dramaturgia. Espacio. Gesto. Teoría. Catástrofe.

${ }^{1}$ Professora Associado IV da Universidade Federal da Bahia (UFBA). Docente permanente do Programa de PósGraduação em Artes Cênicas -UFBA; Docente permanente do Programa de Pós-Graduação em Literatura e cultura da UFBA. cassia.c.lopes@hotmail.com 


\title{
Parte I. O espaço e seus desdobramentos cênicos e filosóficos
}

Em seu sentido etimológico, teatro constitui uma tríade com duas outras palavras: teoria e teorema. Respectivamente, Théatron é o espaço, o lugar de onde se possibilita ver o objeto, o mundo; Theoría, a princípio, já presumiria o olhar contemplativo, portanto o exercício da observação, da prática reflexiva, a que rumina a cena vista; por fim, o Théorema une os dois: é a proposição decorrente do encontro da atuação meditativa e do (-tron) lugar de onde se olha (Nascimento, 1999, p.72). Assim, não é de estranhar que o teatro seja um modo especial de investigar a noção de espaço, tanto de seu ponto de vista social e político, quanto no seu âmbito filosófico. Desse modo, entendemos o motivo que levou o pensador contemporâneo José Gil, em seu livro Os poderes da pintura, a recorrer ao Teatro e seu duplo, de Antonin Artaud, para ampliar suas investigações no modo de ler a dimensão espacial em alguns trabalhos pictográficos contemporâneos, numa crítica evidente a uma arte representacional, portanto mimética. Segundo o autor, Artaud traz a ideia da modelagem do espaço, como pode ser entendido pelo volume de ar que se constrói entre a tela e o corpo do espectador:

\begin{abstract}
Artaud insiste na correspondência entre uma cor e um som, entre o gesto, seu significado intelectual, e o som. Essa tradução imediata de sentido assegura a eficácia do gesto e do som, quer dizer o fato de o gesto, por exemplo, adquirir o valor de uma ação que afeta diretamente o espectador. Para alguém como Artaud, que rejeita a tirania ou mesmo a supremacia da fala e do texto escrito no teatro, o pré-verbal exprime-se numa poderosa linguagem cênica em que os movimentos do corpo desenham hieróglifos a três dimensões. Não se trata de representar Artaud recusa violentamente a representação - mas de ocupar inteiramente o espaço da cena com sons, gritos, gestos que moldam o ar, porque são coisas reais como uma ação real. (Gil, 2015, p. 16-17).
\end{abstract}

Exatamente neste ponto, cria-se a abertura para pensar a dimensão espacial da peça Os arqueólogos, do dramaturgo paulista Vinicius Calderoni, encenada em 2016, em São Paulo, e escolhida para a leitura aqui realizada. Como mapear um texto que traz, para a cena, fragmentos de gestos, de falas, de detalhes corporais vistos como se estivessem sendo filmados ou fotografados por uma câmera? 
Esses gestos moldam o espaço cênico, colocam a dimensão de uma linguagem física, em que tudo parece exceder a palavra e ganhar a estatura de uma imagem em movimento, ou uma tentativa de traduzir, dramaturgicamente, um teatro do espaço em devir, que nasce na medida em que surgem um gesto, um personagem e seus sonhos, com seus devaneios e seus desafios. Na peça citada, defronta-se com a geometria da cidade, a exigir o máximo de concentração na zona dos semáforos, pois, com qualquer movimento em falso, poderá ocorrer uma colisão com eventuais vítimas, ou mesmo um atropelamento: “toda concentração é pouca, luz amarela... luz vermelha, os carros param e... luz verde. Está aberto o sinal de pedestres." (Calderoni, 2018, p. 20).

Nos seus jogos de cores e luzes, o semáforo evoca também a pintura urbana e a trama de intensidades que envolve o movimento dos corpos, as sensações diante da ânsia e do silêncio dos carros parados pela força das determinações da lógica citadina. Nesse aspecto, o drama de Calderoni acaba por visibilizar a geometria do corpo, ou melhor, a maneira como se modela o espaço a partir da perspectiva do gesto, a construir a densidade espacial cênica na visualização das avenidas e esquinas da cidade: "Vemos aí o adolescente com espinhas no rosto e mochila nas costas tomando a dianteira, seguido de perto pelo executivo de paletó e gravata falando ao celular" (Calderoni, 2018, p. 20). Dessa maneira, todos aguardam na faixa de pedestres, na matemática dos sinais, com seus signos de cores, uma pictografia que permite a escuta da ansiedade e a figuração do movimento. Enfim, há toda uma linguagem corporal, coletiva e ao mesmo tempo individual, que ganha destaque na composição do texto, na construção da dramaturgia: a dinâmica dos corpos conquista volume na perspectiva como se dimensiona cada atitude, construindo uma espécie de devir-espaço cênico ou devir de movimentos.

Ocorre a modelagem do espaço por meio da descrição dos mínimos gestos em uma multiplicidade existencial. Desse modo, vemos, na peça, a seguinte cena: "Repare como o vento da passagem dos carros faz o cabelo da moça se deslocar" (Calderoni, 2018, p. 23). Com a construção dramatúrgica que retoma a potência da câmera, para capturar imagens e movimentos, vão surgindo personagens em 
breves quadros dialógicos, com dinâmicas e gestos, por meio dos quais o autor constrói um teatro polifônico, descentrado: "É curioso observar que entre os presentes não há um grito de guerra ou coro articulado, e sim frases desencontradas como 'A gente se fala', 'Você tem horas?' ou 'Olha o amendoim'” (Calderoni, 2018, p. 19). Nessa paisagem marcada pelo fragmento, emerge o conflito entre Maria Paula e Eduardo, com um jogo de palavras reveladoras da incomunicabilidade entre os dois, os desajustes e os desencontros amorosos do casal. Depois, aparecem outros dois personagens: um pai e um filho que está aprendendo a fotografar, a usar uma câmera, a capturar a imagem de uma fonte com chafariz, e disso nasce a reflexão sobre a teoria da arte da fotografia: "A foto pode ter parecido legal, mas de repente, pode ter cruzado um pássaro bem na frente da lente no momento em que foi apertar o botão e então...". (Calderoni, 2018, p. 30).

No diálogo entre os dois personagens, nota-se a interpenetração de duas linguagens artísticas: a fotografia e o teatro. A arte de fotografar, tal como dita pelo pai ao filho, não impede a força de atuação do acaso, e daí pode aparecer um voo de pássaro no meio da imagem; também o texto dramatúrgico deverá estar aberto ao acontecimento, ao imprevisto dos pássaros, de uma palavra que corta a paisagem e muda a cena. Se a arte teatral caracteriza-se pela marca do efêmero, e a fotografia move-se pela força do espectro guardada em cada imagem (Barthes, 1984, p. 14), o que pode um teatro que visibiliza movimentos e imagens como se fosse uma máquina fotográfica ou de instaurar movimento? Se a imobilidade pode resultar de um excesso de dor e de memória, que paralisa músculos e faces, cabe ao teatro produzir um movimento que faça os corpos falarem. Movidos por dores, por medos, por desamparo ou por tantos outros afetos, os músculos podem ser colocados em circulação na cena teatral, e o pensamento passa a ser algo que se faz com o movimento, a partir dele, como se respirasse o oxigênio vindo de cada palavra, numa quebra da prática intelectualizada que silencia os músculos do corpo. Portanto, para elaborar um devir pensamento não é necessário suspender a movimentação corporal.

No ponto de cruzamento entre a Theoría e o Théatron, interessa ver como a 
peça Os arqueólogos permite uma revisão de valores interpretativos dos termos destacados. Nesse caso, nota-se uma teoria da arte de fotografar construída com o dramático. Se a imobilidade da imagem na fotografia não é ausência de movimento, mas a sua fixação, em um recorte do texto, o personagem do pai explica para o filho de dez anos: "Que toda vez que você bate uma fotografia, você para um pedacinho do tempo. Então, enquanto eu tô aqui conversando com você com a minha cara normal, tem uma parte de mim que vai ficar para sempre fazendo aquela careta" (Calderoni, 2018, p. 32). O menino então indaga: "É tipo uma máquina do tempo?” (Calderoni, 2018, p. 32). Bem, esse trecho da peça possibilita ver o cruzamento das linguagens artísticas, suas tensões, mais especificamente uma arte que traz o espectro do vivido, como se algo do passado só pudesse ser plasmado, configurado e instaurado pelo gesto de fotografar. Ao mesmo tempo, o teatro seria o espaço não só de capturar o movimento, mas de produzi-lo e, com isso, também construir um fluxo do pensar.

A theoría, nesse caso, deixaria de ser apenas o exercício contemplativo, tal como se configura no seu primeiro sentido etimológico, pautada na práxis reflexiva, para seguir outro curso avaliativo ao se colocar numa relação com o devir espaço, em movimento. A propósito desse enfoque, esse caminho de leitura pode ser ampliado pelas contribuições de Friedrich Nietzsche que nos possibilita entender a teoria numa outra perspectiva: fora de uma arte puramente contemplativa, assente no cruzamento entre o pensar e o movimento, portanto entre a teoria e o teatro, entre a dinâmica do refletir e o espaço, na inserção do corpo. Em $A$ gaia ciência, no aforismo 6 do Livro I, encontra-se a crítica ao modo de conceituar o ato de pensar na celebração da imobilidade:

Perda da dignidade - A reflexão perdeu toda a sua dignidade da forma, tornaram-se ridículos a cerimônia e os gestos solenes da reflexão, e um homem sábio do velho estilo já não seria tolerado. Pensamos muito rapidamente, andando a caminho, em meio a negócios de toda espécie, mesmo quando pensamos no que há de mais sério; necessitamos de pouca preparação, e mesmo de pouca tranquilidade: - é como se levássemos na cabeça uma máquina incessante, que nas condições mais desfavoráveis ainda trabalha. Antigamente se notava quando alguém queria pensar - era provavelmente excepcional! -, quando queria tornarse mais sábio e se preparava para um pensamento: ele fazia um 
semblante como quem ia rezar e interrompia o passo; permanecia até mesmo horas parado na rua, quando o pensamento "vinha" - andando com apenas uma ou com duas pernas. Assim pedia a dignidade da coisa. (Nietzsche, 2001, p.58-59).

Nesta passagem de Nietzsche, encontra-se a vontade de valorizar outro tipo de pensador, não mais fixado em seu gabinete, com sua ritualística e a aura de grande sábio, mas, ao contrário, um tipo de pensador andarilho, viajante de ruas, aberto ao acaso, que faz do gesto de refletir a produção de um pensamento, inseparável do corpo em trânsito por avenidas, casas, ruas, com seus ruídos e narrativas. Nesse cenário, emerge a theoría também casada à dinâmica do corpotranseunte, em vias de acesso às palavras, às imagens, às ideias percebidas e instauradas com os gestos. Se aqui já se evidencia a reversão do eidos platônico cuja existência jamais poderia nascer da instância corporal e da valorização da matéria sensível, já que a Ideia, para Platão, permanece inalterável, constante e imutável, é possível pensar, contemporaneamente, numa Theoría como campo de ideias mutantes, eternamente cambiantes, em processo de constante vir a ser, no acordo e no acorde da prática teatral, no que esta tem de mais vivo: o deslocarse incansável pelos palcos da vida e da sociedade, no caminhar dos atores, no mover-se das mãos de seus intérpretes. Dessa forma, ocorre a dança peregrina no teatro, mesmo quando, na algaravia do corpo, nada se diz; tudo cala.

O que a dramaturgia contemporânea traz, nos meandros do texto Os arqueólogos, é o declínio de hábitos interpretativos baseados em antinomias, em dualismos que separam a teoria da prática, o corpo do espírito, na esteira das reflexões abertas por Nietzsche como uma pergunta-chave: "Se a filosofia não teria sido apenas uma má interpretação do corpo?” (Nietzsche, 2001, p.12). Cabe ao teatro fazer da palavra um modo de pensar, fazer da palavra também um corpo em movimento, com a sua forma particular de moldar o espaço da cena. Desse modo, no engenho teatral, as palavras pensam, sentem, produzem afeç̧̃̃es. A fala adquire sua força instauradora, palavra-gesto, imagem também em movimento.

Na composição de sua dramaturgia, Calderoni usa o recurso do rádio, com a fala dos noticiadores: um caleidoscópio de vozes e cenas curtas. No meio de uma 
poética do fragmento, surge, então, o repórter Pablo Olaria que apresenta tantos outros personagens para a cena, com seus diferentes espaços. Assim, surge mais um dia de Laura Dellaqua, uma especialista voltada para a atividade inusitada de leitura do corpo: ela conta o tempo que uma pessoa leva para se desfazer de um sorriso dado: "um esporte que pratica desde a infância quando se deu conta de que toda vez que duas pessoas se despedem o sorriso dura um determinado tempo no rosto como resíduo muscular involuntário" (Calderoni, 2018, p. 34). Nesse âmbito textual, ocorre a leitura do gesto que a própria dramaturgia executa como forma de capturar o outro em suas hesitações, em suas nuances sociais, em seus desenhos cotidianos, como se cada um deles fizesse acontecer um modo diferente de existência. Nasce a possibilidade de pensar um corpo pelos gestos que produz, com outra cartografia ontológica: conceber as pessoas pela duração de seus sorrisos, um arabesco gestual que também constitui um espaço ou um modo de modelar o ar.

Nesse aspecto, configura-se uma maneira de pensar o devir espaço dramatúrgico não apenas pela fala instauradora, a marca dialógica, mas um teatro da movimentação dos corpos, em ruas, em cidades, em quartos, com um gesto que instaure um modo diferente de existência. Como indaga David Lapoujade, "É uma questão de direito, mas é mais do que nunca a questão da arte: através de que 'gestos' instauradores as existências conseguem se colocar legitimamente?" (Lapoujade, 2017, p. 25).

É preciso delinear melhor, nesse contexto interpretativo, o modo como se entende o verbo instaurar no campo da atuação dramatúrgica. A primeira ponderação é assinalar que este verbo não significa fundamentar, nem representar ou legitimar uma realidade, dar-lhe consistência material. O fundamento cria algo que ele vai reconhecer; avalia-se o gesto que preexiste ao ato que ele apresenta. Diferentemente, a instauração é inseparável do campo da imanência, pois o gesto é imanente àquilo que instaura; ele não é preexistente, não é mimético. A instauração diz respeito ao próprio gesto. Segundo Lapoujade, "a instauração só se sustenta com seu próprio gesto, nada preexiste a ela. Fundamentar é fazer preexistir, enquanto que instaurar é fazer existir de certa maneira, a cada vez 
(re)inventada." (Lapoujade, 2017, p. 88).

Nesse arco de reflexão, o texto de Vinicius Calderoni possibilita entender que é a voz do Repórter, com seu jogo de sons e palavras, que cria os personagens e o conflito. Também a cena do menino fotografando praças constitui a imagem que não existiria sem o gesto, sem o olhar daquele aprendiz de fotógrafo. Dessa maneira, a peça Os arqueólogos problematiza e constrói uma teoria e um teatro do gesto. E cabe a pergunta: "Não sendo já uma representação que reenviaria a um objeto exterior, mas uma 'coisa' que só reenvia a ela mesma, de onde tira as suas formas e sua própria existência?” (Gil, 2015, p. 22). Esta é a indagação que nos faz José Gil para o entendimento do plano da imanência, na perspectiva do teatro de Artaud. Na avaliação do campo teatral, essa pergunta faz sentido, se ela for considerada para além do palco representacional, se está liberta da prática mimética na forma de conceber o objeto artístico.

Na construção dramatúrgica, o próprio movimento gestual cria o espaço, é imanente, com sua perspectiva singular. O espaço que o teatro engendra é, ao mesmo tempo, o espaço de sua própria gênese; isso significa dizer que não há um antes já posto, acabado, mas um devir espaço cênico que só nasce com a montagem teatral. Nesse enfoque, ainda há que se acentuar a presença do público e, nesse sentido, a cena sai de si e transforma o espaço exterior no qual se situa o espectador, pedindo dele também um devir-movimento, um devir espaço do teatro. Se pensarmos uma dramaturgia, não é possível desconsiderar que os gestos mostram-se valiosos não apenas por instaurarem modos de existência, mas "porque são criadores de direito. É em virtude da amplitude desses gestos, e não de um fundamento exterior, que um modo de existência conquista sua legitimidade." (Lapoujade, 2017, p.89).

Com o texto de Calderoni, nota-se uma dramaturgia feita de sorrisos, de ruídos, de bocejos, de vozes entrecortadas, como um mosaico de cenas e de falas que compõem o ar e, consequentemente, o espaço. Cabe refletir como a escrita forja a cena, pensada geograficamente e, nesse caso, a palavra constrói a dimensão espacial, que já acontece no corpo do texto, no gesto escritural. Portanto, elaborar um texto dramatúrgico já presume, também, construir um 
espaço, não só em suas rubricas, mas na relação do processo de escrita com a experiência vivida, pela ativação da memória e da alucinação da realidade. Retomaria, em certo sentido, a ideia da forma dramática, descrita por Sarrazac sobre uma conferência de Gertrude Stein, quando ela relaciona uma peça teatral a uma paisagem. Segundo o autor, "a característica da paisagem, diz ela, é estar aí" (Sarrazac, 2012, p. 134). Essa posição presume o declínio da ação como célula mater do drama e, consequentemente, a perda do trajeto causalista e linear na construção da curva dramática.

Em Os arqueólogos, a dramaturgia constitui-se de um mundo animado por fendas abertas pelo olhar e pelos campos dos sentidos, voltados para exterioridade no tocante à percepção da geografia urbana e, ao mesmo tempo, na esfera mais inventiva da experiência subjetiva, próximo à atmosfera onírica, onde várias composições de personagens dialogam ao mesmo tempo e se interpenetram numa lógica que excede a causalidade e rompe com a ideia aristotélica do belo animal dramático, quando a imagem de organicidade obedece ao paradigma de uma ação unitária, uma ordem causalista, estipulada pelos termos: princípio, meio e fim. Na peça de Calderoni, não se nota essa totalidade orgânica, com a nostalgia da completude. Ao contrário, situa-se na prática dos rastros e vestígios de vidas humanas.

\section{Parte II: A presença da catástrofe em Os arqueólogos}

Há quem se engane quando almeja uma teoria do drama que se alicerce numa concepção de teatro universalista, portanto unívoca; há ainda os desejosos de uma anatomia do dramático, indiferente à mudança do tempo, das sociedades e dos espaços. A forma dramática, entretanto, não poderá estar alheia às alterações tanto em nível de percepção, quanto em nível de sua expansão nos palcos da vida e de diferentes suportes artísticos. A questão posta cairá, portanto, no modo como a arte dramatúrgica contemporânea experimenta o seu campo de atuação, no meio do turbilhão incessante de demandas sociais, de informações e afetos que atravessam as existências humanas e as linguagens artísticas. 
A propósito dessa ótica transformacional da forma dramática, a peça de Vinicius Calderoni trabalha com duas perspectivas de tempo: a primeira, que antecede a catástrofe, e a segunda, após o evento; o que corresponde, respectivamente, a dois momentos do texto Os arqueólogos. No sentido genealógico do termo, na peça aqui escolhida, a catástrofe não é usada no seu significado clássico, como desenlace trágico de uma ação dramática, com uma intriga construída, na trajetória das ações dos personagens, com seu consequente destino violento, na seta do infortúnio previsto, a exemplo de Édipo Rei ou de Antigona de Sófocles. Nesses últimos dramas, há a lógica da ação que produz dor, violência e desenlace trágico. Já nas formas dramáticas contemporâneas, na peça aqui avaliada, a catástrofe deixa de ser um recurso de mera conclusão do texto, foge à dobra lógica do epílogo da história; ganha sentido mais ampliado. (Sarrazac, 2012, p. 45-47).

Com a teia de fragmentos de falas e gestos, desenvolvida na primeira parte do texto de Calderoni, com a marca da polifonia, na colagem de vários discursos, não se nota a curva dramática linear que desembocaria, inevitavelmente, no desfecho catastrófico. Não se trata de simples solução dramática para o fechamento do texto, mas ganha estatuto de outra ordem, como crítica à dramaturgia clássica, ou mesmo moderna, de acordo com os preceitos de Hegel, para quem ocorreria "um apaziguamento definitivo para o espectador, o lugar de fechamento de sentido" (Sarrazac, 2012, p. 46). No caso de Os arqueólogos, notase o uso ressemantizado do termo catástrofe, pois ganha valor de estatuto crítico, avaliativo; vem associado à história que extrapola a intriga textual. Nesse sentido, a palavra catástrofe aparece, sub-repticiamente, como signo associado à prática dos arqueólogos e também aos termos utilizados na epígrafe: "vestígios de estranha civilização/ bocejos contagiosos" (Calderoni, 2018, p. 17); não versa, portanto, sobre um episódio específico, baseada em um fato descrito, um evento datado historicamente. Surge, por conseguinte, como tema político, associado a guerras, sejam nucleares, sejam as invisíveis, causadas pela explosão de vírus: nomeadamente, as pandemias.

Na peça, desenham-se dados geométricos, falas que emergem ao lado de 
signos cromáticos e vão constituindo a noção de espaço, com suas marcas hieroglíficas deixadas para que os arqueólogos, em tempos posteriores, possam decifrar signos de uma civilização, possivelmente devastada por uma ocorrência catastrófica, já anunciada na epígrafe do texto. Então, os bocejos contagiosos antecipam outra lógica da cidade, e podemos imaginar os semáforos ainda mais tensos, em meio às ruas vazias, cortadas por carros com vidros cerrados, com rostos cobertos por máscaras; com o peso do silêncio nas praças esquecidas, nos museus fechados, nos bares desabitados. E aqui, questiona-se a ordem dada pelo velho arqueólogo na forma como se devem ler as imagens e objetos: sem reinventá-los.

Na segunda parte da peça, emerge o diálogo dos dois arqueólogos, um velho e um jovem, com seus perfis diversos. O primeiro coloca-se como aquele sujeito detentor da experiência, legitimadora de normas de conduta da prática arqueológica. Ele se dirige ao jovem aprendiz com a seguinte assertiva: “- Você já foi informado do protocolo completo" (Calderoni, 2018, p. 48). O jovem arqueólogo responde afirmativamente. Então, o velho arqueólogo informa que ele deverá preencher um questionário, o AVG, o Auto de Verificação Geral, ou seja, terá de seguir todo o ritual exigido, com a necessária disciplina do corpo. Segundo o arqueólogo velho: "Nessa etapa é permitido sentar, caso haja necessidade ou fadiga muscular" (Calderoni, 2018, p. 48). Para a surpresa de todos os leitores, ao preencher o questionário, mostra-se a idade do jovem arqueólogo que já possui 67 anos, trinta anos de carreira como arquivista no Centro de Armazenamento de Dados. Após todo o aparato burocrático de admissão, eis que surge o juramento do arqueólogo recém-contratado:

Eu, arqueólogo, fiel e temente à ordem, conhecedor das normas e consciente da importância da minha função no âmbito coletivo, comprometo-me a não fantasiar, delirar, edulcorar ou tergiversar raciocínios ou fabricar histórias, mantendo a fidelidade absoluta ao preceito básico de reconstruir realidades remotas de modo meticuloso, isento e científico. (Calderoni, 2018, p. 51).

Somente depois do juramento, uma apologia a um tipo de discurso cientificista, a primeira caixa pode ser aberta para análise. Os arqueólogos 
confirmam a paisagem de uma catástrofe, a ideia de um mundo que se foi e só pode ser conhecido por seus vestígios. Os dois personagens, o mais velho e o mais jovem, tomam posse do acontecido pelos rastros, inclusive reencontram a fotografia tirada pelo garoto de dez anos, naquela praça, ao lado de seu pai, como aparece na primeira parte do texto de Calderoni. Ao arqueólogo é imposto um desafio: deve fazer a descrição fiel da imagem fotográfica encontrada, de maneira absolutamente imparcial, sem nenhum tipo de recriação do objeto observado:

ARQUEÓLOGO JOVEM: Vou começar. Item 1: uma fotografia de um grupo de homens e mulheres, de idades variadas, parados diante de veículos em movimento que passam numa via pública. Esse grupo está reunido sobre um pequeno bloco elevado de concreto, todos olham na direção de um sinal luminoso, colocado alguns metros adiante.

ARQUEÓLOGO VELHO: Registro. Esse sinal luminoso para o qual esse grupo de pessoas olha representa uma tentativa ainda muito primitiva do controle das interações humanas e dos comandos motores. Contudo, há que se notar a completa insuficiência desse recurso: assim, que se acendia a cor verde no farol luminoso, cada um desses indivíduos estava autorizado a andar na direção que bem entendesse, o que ajuda a dimensionar o caos em que viviam. Repare bem na imagem o sentido absoluto de desordem: as peles se encostam, na grande maioria das vezes sem proteção, sem que isso pareça ser um problema, todos cegos do real perigo a que estavam expostos. Avante. (Calderoni, 2018, p. 53).

A dramaturgia de Calderoni não se definiria pela simples expressão da realidade pós-catastrófica, pois já revela uma catástrofe em curso, a exemplo do que fez Samuel Beckett, em sua obra Catástrofe (Beckett, 1984). De certo modo, já se antecipa o perigo que só ganharia o sentido concreto dos fatos em 2020. Quando foi escrita esta peça, em 2016, o autor jamais imaginaria que o Brasil e o mundo passariam por uma pandemia, com todo o sentido mortífero diante da maneira destrutiva como a maioria dos seres humanos vem habitando o planeta. Para a leitura do cenário da grande crise sanitária e política do século XXI, essa dramaturgia acaba trazendo a dimensão política, ao desenhar a degenerescência de um projeto civilizacional, exatamente no ponto em que as pessoas temem as outras, não só como perigo de contágio, com o aceno da morte, mas pelas práticas violentas pautadas em desigualdades sociais.

Como lidar com um público tão sofrido, todos com máscaras, com medo de 
um espirro, de uma fala mais próxima, de um toque de mão? E de fato, é impossível manter uma arte mimética, sob o clima de uma catástrofe muito tangível, quando o ator, entregue ao palco, poderá sofrer o contágio. Consequentemente, o público também reagirá à cena dos personagens arqueólogos, que abrem caixas para análise, como restos de uma "estranha civilização", com os sentimentos que o espectador não teria, se não houvesse passado por essa experiência pandêmica. Deste modo, o sentido catastrófico, anunciado textualmente nos "bocejos contagiosos", ganha a dimensão real e complexa dos fatos no rosto de cada espectador.

Assim, há o teatro que nos deixa ver a fragilidade de um projeto civilizacional, na ancoragem de um tipo de razão cientificista e das leis de regulação de mercado, que se desmonta por não saber lidar com um vírus invisível. Se o teatro é o espaço onde se deixa ver o objeto, cabe agora tornar-se a arte que joga com a força microscópica, imperceptível do próprio vírus, que só pode ser pressentida quando no contato com outro corpo. Evidentemente, são ponderações feitas que extrapolam o texto do Calderoni, mas sugeridas por ele, numa leitura que não pode ficar indiferente ao cenário histórico, pandêmico, de 2020. Afirma-se, nesse caso, uma dobra do texto dramatúrgico que deságua numa leitura do cenário social e político da atualidade, em nível mundial. Constata-se uma aflição entre artistas, atores, escritores diante desse quadro catastrófico, sugerido por Calderoni, numa perspectiva que antes seria impossível. Nesse trajeto, a arte, com suas ferramentas do imaginário, suas voltagens de criação, traz para a escrita algo que se concretizou na realidade, com proporções inconcebíveis. Logo, constata-se a emergência de um campo de forças invisíveis que toma o centro do tablado, mesmo que o público seja remoto ou diminuto, ou o teatro esteja vazio. Estamos diante da arte dramatúrgica que, de alguma forma, problematiza o ocaso de um tipo de teatro, ancorado em práticas civilizacionais estabelecidas, pois, quando ocorre uma pandemia na qual as falas são temidas, porque se tornam contagiosas, o tablado dos atores e o texto criado para grande público correm o risco de não serem ouvidos e, mesmo que sejam postos em cena, não se eliminam o medo, o temor da contaminação, embora todos os espectadores estejam mascarados. 
Diante disso, a máscara, a persona teatral, generaliza-se, e todos os espectadores participam como coro de um espetáculo para o qual não se sabiam preparados.

Se na pós-pandemia, de 2020, é impossível dividir o mundo em esferas dicotômicas, a exemplo do binômio ocidental e oriental, pois o contágio se fez em escala globalizada, há algo de terrível, nesse quadro da civilização, que se concretiza no controle do movimento dos corpos também em escala global. Nesse caso, o vírus será a coroação de um projeto que já estava em curso: sugere-se que os seres humanos vivam virtualmente, por meio de aparato tecnológico, passando mensagens, fazendo fotos da rotina de suas casas, para tentar divulgar, para outro olhar, a sua existência e, com isso, burlar a solidão e o sofrimento. Com a realidade pandêmica, essa tendência se acentua: exige-se que as pessoas sejam olhadas, expostas, vigiadas, com suas temperaturas controladas; espera-se que se guardem em suas casas, com os limites rígidos da liberdade de circulação. Mas aqui está o maior perigo: a massificação semiótica. Todas as postagens giram em torno de um mesmo vírus, de um mesmo foco, das mesmas imagens.

Nesse contexto, a teoria andarilha, afeita à escuta de ruas, atenta aos semáforos, desenhada na primeira parte do texto Os arqueólogos, deverá produzir outro tipo de nomadismo: aquele cuja prática não requer que o corpo se locomova por diferentes espaços concretos, pois se consideram diversas tipologias de viajantes e de andarilhos. Tendo em vista a dimensão do paradoxo, há os que se dirigem para outros ambientes e países, mas tiram as fotografias previsíveis; nesse sentido, continuam com suas mesmas formas de vida, sedentários, presos a seus valores. Já há outros andarilhos que não saem de seus territórios físicos, no entanto deambulam por outras paisagens afetivas e existenciais, no encontro com diferentes alteridades. Assim, na escrita polifônica e descentrada de Calderoni, nos vários exemplos já elencados, nota-se a vontade de não se centrar em uma única célula dramática, em um personagem protagonista, caracterizando-se, portanto, como uma escrita em si mesma nômade, heterogênea. (Deleuze. 1997)

Em se tratando de uma dramaturgia no desenho de ambiente catastrófico, talvez o teatro de Artaud traga possibilidade para pensar o homem nômade e seu espaço, tal como sugerido na peça Os arqueólogos e em situação de pandemia, 
na qual o corpo social padece e, talvez daí, possa ser levado a reinventar seu modo de existência. Em tempos pandêmicos, convoca-se a imaginação para que seja ativada em sua força máxima, com sua capacidade criadora, sob pena de o homem sucumbir nos seus dias, tornando-se, ainda mais, uma máquina de manobra, um corpo dócil, dominado pelo pânico. No âmbito dessa reflexão, quando refletiu sobre a Peste, ocorrida em 1502, em Provence, e a de 1720, em Marselha, Antonin Artaud tentou justamente captar a força do teatro que deveria ser análoga à da peste, mas não por seu contágio:

Se o teatro é essencial como a peste não é por ser contagioso, mas sim porque, como a peste, é a revelação, a ascensão para o primeiro plano, a exteriorização de um fundo de crueldade latente através da qual se localizam num indivíduo ou num povo todas as possibilidades perversas do espírito. (Artaud, 1987, p.43).

É pertinente a analogia entre o teatro e a peste nesse contexto de leitura da peça de Calderoni. Primeiro motivo, porque, segundo Artaud, há uma dimensão da vida que se revela em situação de pandemia, de catástrofe: um feixe de intensidades, de sensações reprimidas pela normatização do cotidiano que a pandemia questiona: "[...] a ação do teatro, como a da peste, é benfazeja, pois, levando os homens a se verem como são, faz cair a máscara, põe a descoberto a mentira, a tibieza, o engodo" (Artaud, 1987, p.45). Mas também Artaud nos deixa ver que "a ação do teatro sacode a inércia asfixiante da matéria que atinge até os dados mais claros dos sentidos" (Artaud, 1987, p.45). O segundo motivo da analogia nasce do fato de o vírus convocar uma rede de forças que leva o homem a se defrontar com seus conflitos e, nesse aspecto, ocorre também a liberação de possibilidades de vidas cativas. Se a crise proporcionada pela situação pandêmica traz o medo como seu maior afeto, e prevê as perdas com seus gritos de dor, há também um potencial de imagens, de instâncias criadoras, que eclodem numa situação de pandemia. Este é o desafio deixado pelo teatro da catástrofe: fazer da morte a convocação às forças da vida, à construção de outros espaços! 


\section{Referências}

ARTAUD, Antonin. O teatro e seu duplo. 3. Ed. São Paulo: Limonax, 1987.

BARTHES, Roland. A câmara clara: nota sobre a fotografia. Trad. Júlio Castañon Guimarães. Rio de Janeiro: Nova Fronteira, 1984.

CALDERONI, Vinicius. Os arqueólogos. Rio de Janeiro: Cobogó, 2018.

DELEUZE, Gilles; GUATARRI, Félix. Tratado de nomadologia: a máquina de guerra. In: Mil Platôs - capitalismo e esquezofrenia. Trad. Peter Pál Pelbart e Janice Caiafa. São Paulo: Ed. 34, 1997. 5.v. p.11-110.

GIL, José. Poderes da pintura. Lisboa: Relógio D’Água, 2015.

LAPOUJADE, David. As existências mínimas. Trad. Hortência Santos Lencastre. São Paulo: N-1 Edições, 2017.

NASCIMENTO, EVANDO. Derrida e a literatura: "notas" de literatura e filosofia de desconstrução. Niterói: EdUFF, 1999.

NIETZSCHE, Friedrich. A gaia ciência. Trad. Paulo César de Sousa. São Paulo: Companhia das Letras. 2001.

SAMUEL, Beckett, Catástrofe. Trad. Flávio de Campos. In: Cadernos de teatro. Rio de Janeiro: O tablado, n. 102. Jul/ago/set. 1984. p.17-18. Disponível em:

<http://otablado.com.br/wp-content/upçoads/npteboostheater/4053b193cb79fccf60e8822d34d43679>. Acesso em: 10 jun. 2020.

SARRAZAC, Jean-Pierre. (Org.) Léxico do drama moderno e contemporâneo. Trad. André Telles. São Paulo: Cosac Naify, 2012.

Recebido em: 17/06/2020

Aprovado em: 30/07/2020 